\title{
Influence of inhaler technique on asthma and COPD control: a multicenter experience
}

\author{
This article was published in the following Dove Press journal: \\ International Journal of COPD \\ 6 October 2016 \\ Number of times this article has been viewed
}

\begin{abstract}
Aleksandra Dudvarski Ilic ${ }^{1,2}$ Vladimir Zugic ${ }^{1,2}$

Biljana Zvezdin 3,4

Ivan Kopitovic ${ }^{3,4}$

Ivan Cekerevac ${ }^{5,6}$

Vojislav Cupurdija ${ }^{5,6}$

Nela Perhoc ${ }^{7}$

Vesna Veljkovic ${ }^{7}$

Aleksandra Barac ${ }^{8}$

'Faculty of Medicine, University of Belgrade, ${ }^{2}$ Clinic for Pulmonology,

Clinical Centre of Serbia, Belgrade, ${ }^{3}$ Faculty of Medicine, University of Novi Sad, Novi Sad, ${ }^{4}$ Institute for Pulmonary Diseases of Vojvodina, Sremska Kamenica, ${ }^{5}$ Faculty of Medicine, University of Kragujevac, ${ }^{6} \mathrm{Clinic}$ for Pulmonology, Clinical Centre Kragujevac, Kragujevac, ${ }^{7}$ Clinic for Pulmonary Diseases Knez Selo, Clinical Centre Nis, Nis, ${ }^{8}$ Faculty of Stomatology, University Academy of Business Novi Sad, Novi Sad, Serbia
\end{abstract}

Correspondence:Aleksandra Dudvarski Ilic

Clinic for Pulmonology, Clinical Center of Serbia, Koste Todorovica 2, Belgrade I1000, Serbia

Email sanjadudvarski@yahoo.com
Background: The successful management of asthma and chronic obstructive pulmonary disease (COPD) mostly depends on adherence to inhalation drug therapy, the usage of which is commonly associated with many difficulties in real life. Improvement of patients' adherence to inhalation technique could lead to a better outcome in the treatment of asthma and COPD.

Objective: The aim of this study was to assess the utility of inhalation technique in clinical and functional control of asthma and COPD during a 3-month follow-up.

Methods: A total of 312 patients with asthma or COPD who used dry powder Turbuhaler were enrolled in this observational study. During three visits (once a month), training in seven-step inhalation technique was given and it was practically demonstrated. Correctness of patients' usage of inhaler was assessed in three visits by scoring each of the seven steps during administration of inhaler dose. Assessment of disease control was done at each visit and evaluated as: fully controlled, partially controlled, or uncontrolled. Patients' subjective perception of the simplicity of inhalation technique, disease control, and quality of life were assessed by using specially designed questionnaires.

Results: Significant improvement in inhalation technique was achieved after the third visit compared to the first one, as measured by the seven-step inhaler usage score (5.94 and 6.82, respectively; $P<0.001)$. Improvement of disease control significantly increased from visit 1 to visit $2(53.9 \%$ and $74.5 \%$, respectively; $P<0.001)$ and from visit 2 to visit $3(74.5 \%$ and $77 \%$, respectively; $P<0.001)$. Patients' subjective assessment of symptoms and quality of life significantly improved from visit 1 to visit $3(P<0.001)$.

Conclusion: Adherence to inhalation therapy is one of the key factors of successful respiratory disease treatment. Therefore, health care professionals should insist on educational programs aimed at improving patients' inhalation technique with different devices, resulting in better long-term disease control and improved quality of life.

Keywords: Turbuhaler, adherence, inhalation technique, asthma, COPD

\section{Introduction}

Respiratory diseases are the fourth leading cause of mortality in the world, ${ }^{1}$ while chronic respiratory diseases, chronic obstructive pulmonary disease (COPD), and asthma are among the ten leading causes of death in Serbia, as reported in annual Health Statistical Yearbook of the Republic of Serbia. ${ }^{2}$

In 2014, almost 127,000 Serbian people suffered from chronic respiratory diseases. ${ }^{1}$ Smoking, which is one of the most important risk factors for the development of respiratory diseases and a widespread habit among Serbian people, could be an explanation for the epidemic rise of chronic obstructive respiratory diseases among Serbian population.

There are some reports suggesting that current management of COPD and asthma is not optimal in many patients, despite considerable improvement of 
therapeutic options. ${ }^{3}$ It is proposed that this therapy failure could be attributed to low patient adherence to inhaler technique, lack of knowledge, and inappropriate education about the use of this kind of long-term therapy. ${ }^{4}$ According to the results of several European studies, $50 \%-60 \%$ of asthma/ COPD patients have poor control of the disease, probably due to poor adherence to the prescribed treatment, especially to inhaler devices. ${ }^{2,3}$

Improvement of patients' adherence to inhalation technique could lead to better outcome of treatment of asthma and COPD. The aim of this study was to assess the utility of dry powder inhalation technique in the clinical and functional control of asthma and COPD during 3-month follow-up period, by evaluation of the level of disease control and changes in patient quality of life.

\section{Materials and methods Study population}

The study (NIS-RRS-XXX-2011/1) was conducted in nine secondary/tertiary centers in Serbia during the years 2011 and 2012, and included 312 asthma or COPD patients. The patients were observed during three monthly visits. The sample size was determined according to the recommendations of the Research Program Steering Committee. It was estimated that a minimum of 30 physicians were needed for the representative sample and at least 300 patients should be enrolled in the study as the representative sample of the population. Inclusion criteria were: 1) age $>18$ years, 2) diagnosis of asthma or COPD, and 3) use of dry powder inhaler therapy (Turbuhaler). The exclusion criterion was patient's participation in any other clinical trial.

\section{Study design}

The study design involved evaluation of patients' 1) assessment (simple, moderate, difficult to use) of usage of the inhaler device, which was achieved through specially designed questionnaires, 2) understanding of its benefits in the long-term control of symptoms, and 3) understanding of its impact on quality of life. Collection of data concerning patient's sociodemographic characteristics and comorbid conditions was also performed using specially designed questionnaires and by subjective assessment of intensity of symptoms such as wheezing, coughing, and dyspnea (shortness of breath). Estimation of quality of life level in asthma/COPD patients was done by determining the "quality of life score" calculated as the sum of answers to the questions on the following: 1) frequency of respiratory symptoms during the night and day and 2) inability to perform everyday activities.
This score could range from a minimum of 3 to a maximum of 12 , with higher scores meaning better quality of life.

(a) During three visits (once a month), training was given in seven-step inhalation technique which consisted of: 1) unscrewing and removing the protective cover, 2) holding the device upright, 3 ) twisting the grip on the base to the right (till the end) and then to the left (till the end), until the sound "click" is heard, 4) breathing out slowly, away from the device mouthpiece, 5) placing the mouthpiece gently between the teeth and taking a deep breath, 6) taking out the device from the mouth, holding the breath for 10 seconds, breathing out, and 7) replacing the protective cover firmly. Correctness of the seven-step inhalation technique was measured by giving a score of 1 for correct action and 0 for incorrect action. Each of the seven steps was scored 1 or 0 , giving a total score of $0-7$. The total score was calculated.

(b) During each visit, global assessment of disease control was done by pulmonologists after clinical examination. This was categorized as: 1) fully controlled, 2) partially controlled, and 3) uncontrolled. ${ }^{3}$

(c) Patients had different options for receiving education on device usage: 1) self-learning - patients are educated by their caregiver, but without practical demonstration; 2) by nonspecialized medical staff - nurses, primary care physicians, or pharmacists; or 3) by pulmonologists - practical demonstration and education was the method used for teaching patients during their visits. Appropriate option was indicated in the questionnaire by the patients.

(d) The patient questionnaire was validated during documentation preparation phase. Before starting the study, the questionnaire was piloted on ten patients of different ages and educational backgrounds (five with asthma and five with COPD), in order to check whether the questions were clearly formulated and understandable to the respondents. Before they were given a questionnaire, participants had been informed that the information collected would remain anonymous and that participation was entirely voluntary.

Individual results from all nine medical centers included in the study were collected and evaluated as a whole. The study was conducted in accordance with the Declaration of Helsinki and Good Clinical Practice guidelines, and approved by the ethics committee of Clinical Centre of Serbia, ethics committee of Clinical Centre of Kragujevac, ethics committee of Clinical Centre of Nis, and ethics committee of Clinical Centre of Institute for pulmonary 
diseases Kamenica. All patients read and signed the informed consent form.

\section{Statistical analysis}

Descriptive and inferential statistical analyses were used for evaluation of data using Statistical Package for Social Sciences (SPSS 17.0) (SPSS Inc., Chicago, IL, USA). Data were expressed as mean \pm standard deviation (SD) and counts or percentages while describing continuous data with normal distribution, whereas non-normal data were described as median and lower and upper quartiles. Categorical data were described by absolute number and percentage of subjects per category. Mann-Whitney $U$-test was used for intergroup comparison. Friedman test for nonparametric repeated measures followed by Wilcoxon signed-rank test or paired $t$-test were used, where appropriate, for paired data comparison. Cochran's $Q$ test was used to determine change in the proportion of participants regarding their correctness of device usage between the three visits.

\section{Results \\ Clinical characteristics and sociodemo- graphic data of the study group}

The study group consisted of 312 patients with COPD or asthma. Among the patients, $74 \%$ had asthma while $24 \%$ had COPD. Male to female (M:F) ratio was $1: 1.54$. There were no differences in disease stage between patients with asthma and COPD (Table 1). Comorbidities were present in $42 \%$ of patients, with hypertension $(20.2 \%)$ and allergic rhinitis $(5.1 \%)$ being the most prevalent (Table 2 ).

Most common chronic respiratory disease risk factors assessed in the study group were: smoking (58\%), positive

Table I Sociodemographic and disease-related characteristics of the patients observed in nine clinical centers/hospitals

\begin{tabular}{|c|c|c|c|}
\hline \multirow[t]{2}{*}{ Variable } & \multicolumn{3}{|c|}{ Total patients 312 ( $100 \%)$} \\
\hline & Asthma & COPD & P-value* \\
\hline Number of patients, n (\%) & $231(74)$ & $81(26)$ & $<0.001$ \\
\hline $\begin{array}{l}\text { Duration of disease in years } \\
\text { (mean } \pm S D)\end{array}$ & $5.2 \pm 1.7$ & $6.5 \pm 3.4$ & ns \\
\hline $\begin{array}{l}\text { Duration of any kind of therapy } \\
\text { in years (mean } \pm S D \text { ) }\end{array}$ & $5.4 \pm 1.9$ & $5.5 \pm 2.3$ & ns \\
\hline $\begin{array}{l}\text { Duration of therapy with inhaler } \\
\text { device in years (mean } \pm S D \text { ) }\end{array}$ & $1.3 \pm 0.7$ & $\mathrm{I} . \mathrm{I} \pm 0.8$ & ns \\
\hline $\mathrm{M}: \mathrm{F}$ ratio & \multicolumn{2}{|c|}{ I:I.54 } & \\
\hline Age in years (mean $\pm S D)$ & \multicolumn{2}{|c|}{$51.8 \pm 17.3$} & \\
\hline
\end{tabular}

Notes: Cities: Belgrade (five centers), Novi Sad (one center), Niš (one center), Kragujevac (one center), Sombor (one center). *Mann-Whitney U-test.

Abbreviations: COPD, chronic obstructive pulmonary disease; M:F, male to female ratio; ns, nonsignificant difference; SD, standard deviation.
Table 2 Comorbidities of the study population

\begin{tabular}{ll}
\hline Disease & $\mathbf{n ~ ( \% )}$ \\
\hline Allergic rhinitis & $16(5.1)$ \\
Cardiovascular disease & $17(5.4)$ \\
Hypertension & $63(20.2)$ \\
Diabetes mellitus & $12(3.8)$ \\
Gastrointestinal disease & $5(1.6)$ \\
Neurological disease & $1(0.3)$ \\
Other & $2(0.6)$ \\
Without comorbidity & $181(58.0)$ \\
\hline
\end{tabular}

family history for respiratory diseases $(33 \%)$, and exposure to fumes (12.5\%) (Table 3).

\section{Evaluation of source of patients' education about inhaler device usage}

Analysis of the data about origin of patients' education of inhaler device usage showed that visits to pulmonologists were the primary way of education for the patients with COPD/asthma. Number of self-learning patients in device usage decreased to half from visit 1 to visit 3 (Figure 1). From the first to the third visit, the number of patients with the answer "simple" regarding inhaler device usage was significantly increased $(90.5 \%-98 \%$, respectively; $P<0.001)$.

\section{Comparison of correctness of usage of dry power inhalers between visits $I$ and 3}

The results of the seven-step inhalation technique tests are shown in Table 4 for each visit.

The percentages of correct inhaler usage for almost all of the seven steps were initially high (above 90\% for steps 1 and 7 , above $80 \%$ for steps 2 and 5, and above $70 \%$ for steps 3 , 4 , and 6), but statistically significant improvement was evident through the visits 2 and 3 for steps $2-6(P<0.001)$. For steps 1 and 7, there was no significant increase in correctness of usage, as their correctness was already assessed to be almost $100 \%$ at the first visit (Table 4 ).

Table 3 Risk factors for development of respiratory diseases in the study population

\begin{tabular}{ll}
\hline Risk factors & $\mathbf{n}(\%)$ \\
\hline Current smoker & $48(15.4)$ \\
Ex-smoker & $\mathrm{I} 33(42.6)$ \\
Family history for asthma or COPD & $103(33.0)$ \\
Allergic rhinitis & $16(5.1)$ \\
Exposure to fumes & $39(12.5)$ \\
Other & $17(5.4)$ \\
\hline
\end{tabular}

Abbreviation: COPD, chronic obstructive pulmonary disease. 


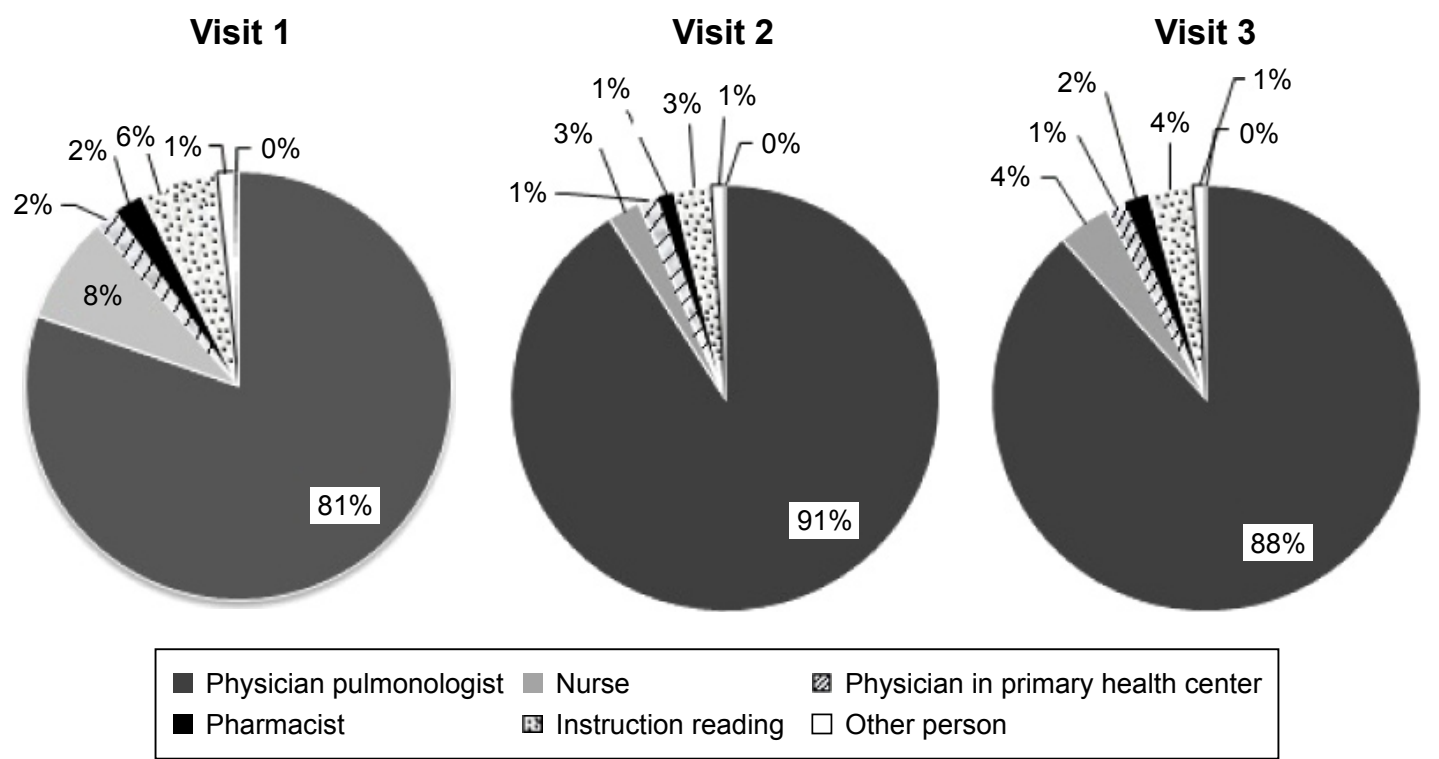

Figure I Different modalities of patients' practical education on inhaler device usage during three visits.

At the first visit, the weakest points of inhaler usage were steps 3, 4, and 6. However, these steps showed the highest statistically significant improvement at visit 3 (about 20\%, $P<0.001$ ) (Table 4). Inhaler score was calculated for all patients after each visit and the average values are shown in Figure 2. Inhaler score consistently increased from visit 1 to visit 3 . Assessment of disease control evidenced its improvement from visit 1 to visit 2 (53.9\% and $74.5 \%$, respectively; $P<0.001)$ and from visit 2 to visit $3(74.5 \%$ and $77 \%$, respectively; $P<0.001$ ) (Figure 3 ).

\section{Comparison of patients' subjective} assessment of symptoms at visits I and 3

Significant improvement was noted in patients' subjective assessment of the frequency and intensity of symptoms when comparing visit 1 to visit $2(P<0.001)$, visit 1 to visit $3(P<0.001)$, and also visit 2 to visit $3(P<0.01)$. The percentage of patients experiencing the symptoms every night decreased by half (from almost $10 \%$ to below $5 \%$ ). The percentage of patients who had disease-related symptoms one to two nights per week decreased from $18 \%$ at visit 1 to $13 \%$ at

Table 4 Correctness of patients' usage of DPI device in COPD or asthma patients

\begin{tabular}{|c|c|c|c|c|c|}
\hline \multirow[t]{2}{*}{$\begin{array}{l}\text { No of } \\
\text { step }\end{array}$} & \multirow[t]{2}{*}{ Seven steps of inhalation technique } & \multicolumn{3}{|c|}{$\begin{array}{l}\text { Total no of patients who correctly used DPI } \\
\text { device, n (\%) }\end{array}$} & \multirow[t]{2}{*}{$P$-value* } \\
\hline & & Visit I & Visit 2 & Visit 3 & \\
\hline 1 & Unscrew and lift off the cover, $n(\%)$ & $307(98.4)$ & $283(99.3)$ & $303(100)$ & 0.066 \\
\hline 2 & Holding the inhaler upright, $\mathrm{n}(\%)$ & $270(86.5)$ & $264(92.6)$ & $296(97.7)$ & $<0.001$ \\
\hline 3 & $\begin{array}{l}\text { Turning the red grip as far as it will go to the } \\
\text { right, then turning it as far as it will go to the } \\
\text { left. A "click" sound is heard, } n(\%)\end{array}$ & $247(79.4)$ & $266(93.3)$ & $291(96)$ & $<0.001$ \\
\hline 4 & $\begin{array}{l}\text { Breathing out gently to the end and far from } \\
\text { inhaler mouthpiece, } n(\%)\end{array}$ & $235(75.3)$ & $252(88.4)$ & $288(95)$ & $<0.001$ \\
\hline 5 & $\begin{array}{l}\text { Placing the mouthpiece gently between the } \\
\text { teeth, deep breath, } \mathrm{n}(\%)\end{array}$ & $269(86.2)$ & $275(96.5)$ & $297(98)$ & $<0.001$ \\
\hline 6 & $\begin{array}{l}\text { Removing the inhaler from the mouth. Holding } \\
\text { breath for about } 10 \mathrm{sec} \text {. Breathing out, } \mathrm{n}(\%)\end{array}$ & $244(78.2)$ & $267(93.7)$ & $293(96.7)$ & $<0.001$ \\
\hline 7 & Replacing the cover tightly after use, $\mathrm{n}(\%)$ & $306(98.1)$ & $282(98.9)$ & $301(99.3)$ & 0.236 \\
\hline & Total number of patients per visit & $312(100)$ & $285(100)$ & $303(100)$ & \\
\hline
\end{tabular}

Note: *Cochran's $Q$ test.

Abbreviations: COPD, chronic obstructive pulmonary disease; DPI, dry powder inhaler. 


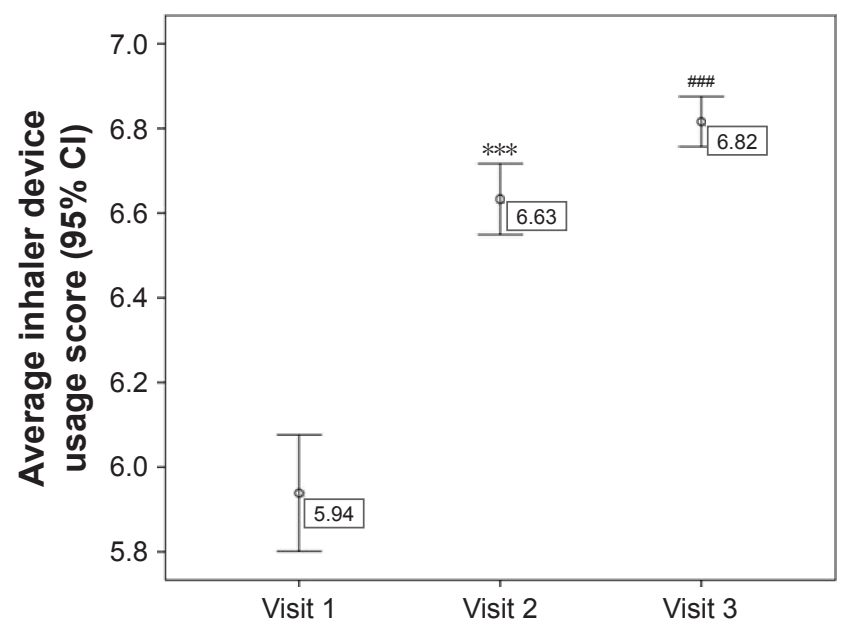

Figure 2 Comparison of mean values of inhaler device usage score between visit I and visit 2, and visit I and visit 3 .

Notes: ${ }^{* * *}$ Visit I versus visit $2, P<0.00$ I, Student's $t$-test; ${ }^{\prime}$ visit I versus visit 3 $P<0.00$ I, $t$-test.

Abbreviation: $\mathrm{Cl}$, confidence interval.

visit 3. Comparison of frequency of symptom onset between visits 1 and 3 revealed statistically significant decrease: from $14.8 \%$ to $4.3 \%(P<0.001)$ for everyday symptoms and from $24.59 \%$ to $13.4 \%(P<0.001)$ for one to two attacks per week. Patients' answers related to their regular everyday activities and their inability to perform them due to disease worsening were compared between visits 1 and 3 . We concluded that the most frequent disturbances decreased from $12.1 \%$ to $4.3 \%$ for every day symptoms $(P<0.001)$ and from $19 \%$ to $10.7 \%$ $(P<0.001)$ for one to two attacks per week (Figure 4).

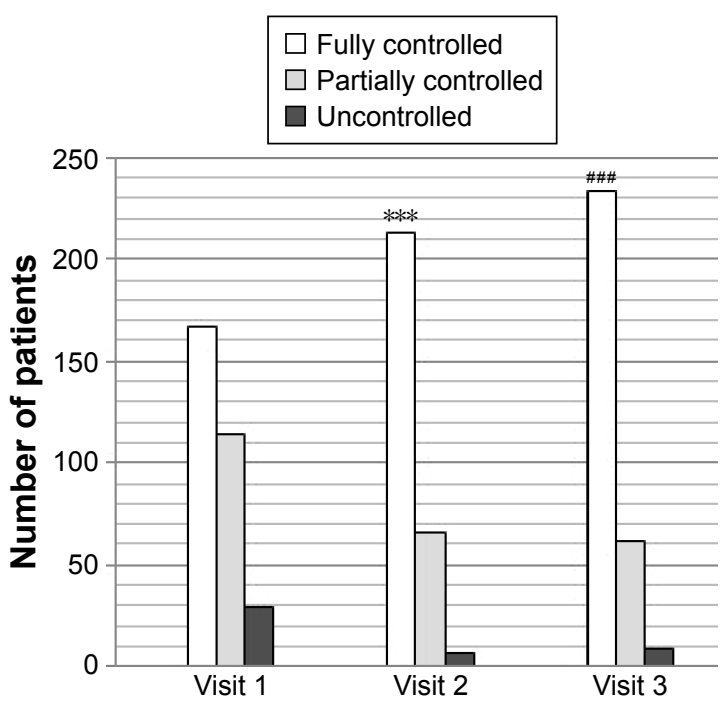

Figure 3 Comparison of global assessment of disease control between visit I and visit 2, and visit I and visit 3 .

Note: ***Visit I versus visit 2, $P<0.00$ I; Visit I versus visit 3, $P<0.00$ I, Wilcoxon signed-rank test.

\section{Comparison of "quality of life" score results between visits I and 2, and visits I and 3}

Statistically significant improvement in the results of "quality of life" score was evidenced after visit 2 in comparison to visit 1 , and after visit 3 in comparison to visit $1(P<0.001$ for both) (Figure 5).

\section{Discussion}

As for the success of chronic airways disease treatment, only $10 \%$ accounts for medication and $90 \%$ is the result of education in inhaler device usage. ${ }^{4,5}$ According to the results of several studies, poor clinical control and increased number of hospitalizations are frequently caused by poor adherence of patients to inhaler therapy. ${ }^{4,6,7}$ Prospective studies are needed in order to estimate the value of educational interventions aimed at overcoming the difficulties of inhalation technique. This is the first study in Serbia that could be used to reach a conclusion on the adherence of patients in neighboring countries where similar studies have not been conducted. It is particularly important to determine the degree of adherence to this type of therapy and to assess how this type of training improves the overall status of the patient, because these data are lacking for developing countries or countries with lower economic status. The significance of this study is that the results can be used for pharmacoeconomic analysis that would show how to reduce the cost of treating patients with proper education and correct adherence. Our analyses revealed the following: 1) significant improvement in inhalation technique was achieved after third visit compared to the first one; 2) the most common risk factors of chronic respiratory disease were smoking (58\%), positive family history for respiratory diseases (33\%), and exposure to fumes (12.5\%); 3) seven-step inhaler usage score was significantly increased from the first to the third assessment (5.94 and 6.82, respectively; $P<0.001)$; 4) improvement of disease control significantly increased from visit 1 to visit $2(53.9 \%$ and $74.5 \%$, respectively; $P<0.001)$ and from visit 2 to visit 3 (74.5\% and 77\%, respectively; $P<0.001$ ); and 5) patients' subjective assessment of symptoms and quality of life significantly improved from visit 1 to visit $3(P<0.001)$.

Development of dry powder inhaler inhalers looks promising with easier use and less technical errors compared to metered dose inhalers. ${ }^{8,9}$ A large multicenter study that compared these two techniques reported almost equal percentage of patients who failed concerning the critical steps in their usage. ${ }^{10}$ Melani et al noted that patients often lacked proper 

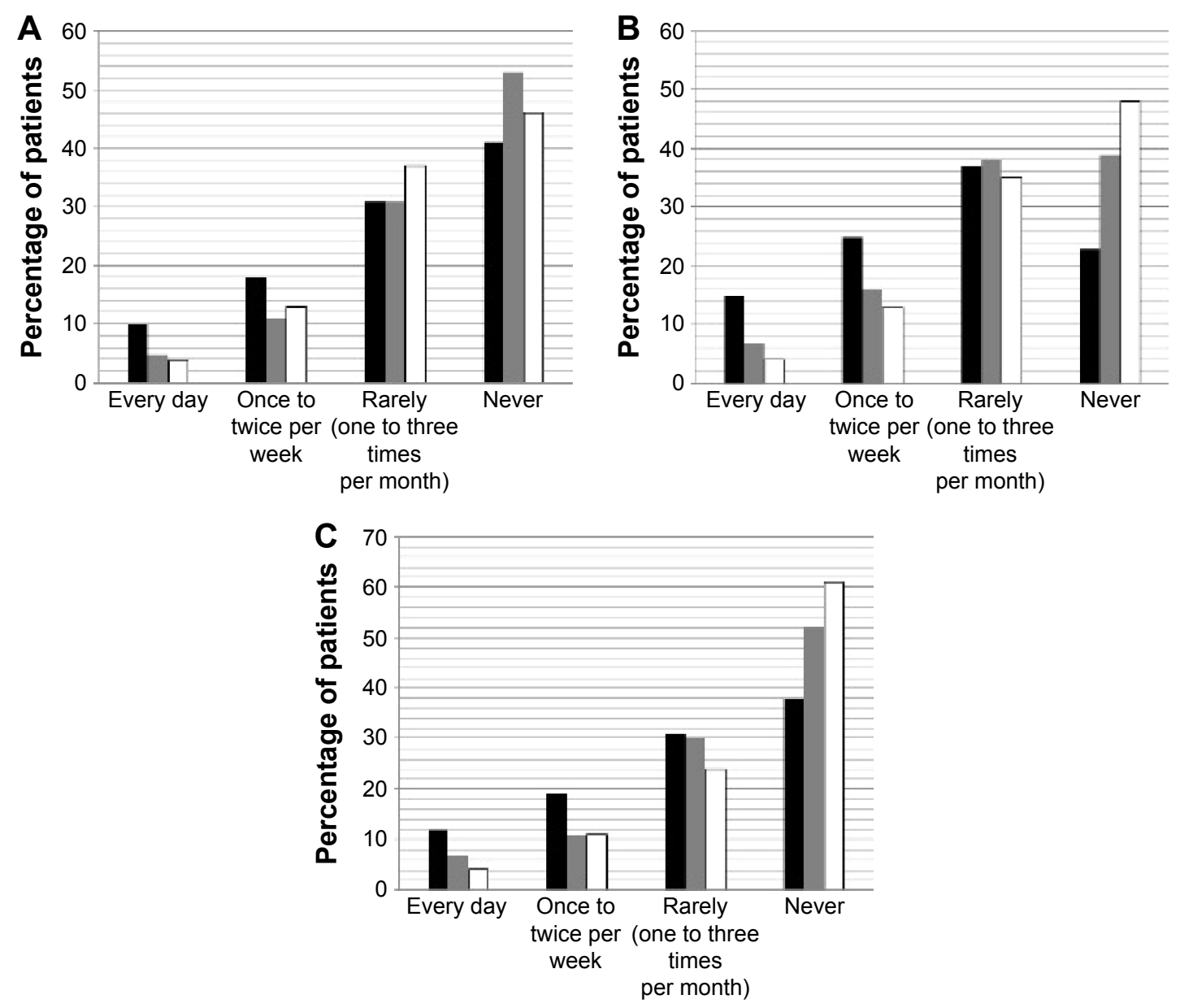

Visit $1 \square$ Visit $2 \square$ Visit 3

Figure 4 Patients' questionnaire regarding respiratory disease symptoms (wheezing, coughing, and shortness of breath).

Notes: (A) During the night, $(\mathbf{B})$ during the day, $(\mathbf{C})$ disturbance of everyday activities (percentage of patients and frequency of symptoms in every visit). $(\mathbf{A}) \chi^{2}=10.1, P<0.05$; (B) $\chi^{2}=18.1, P<0.01 ;$ (C) $\chi^{2}=7.8, P=0.096$.

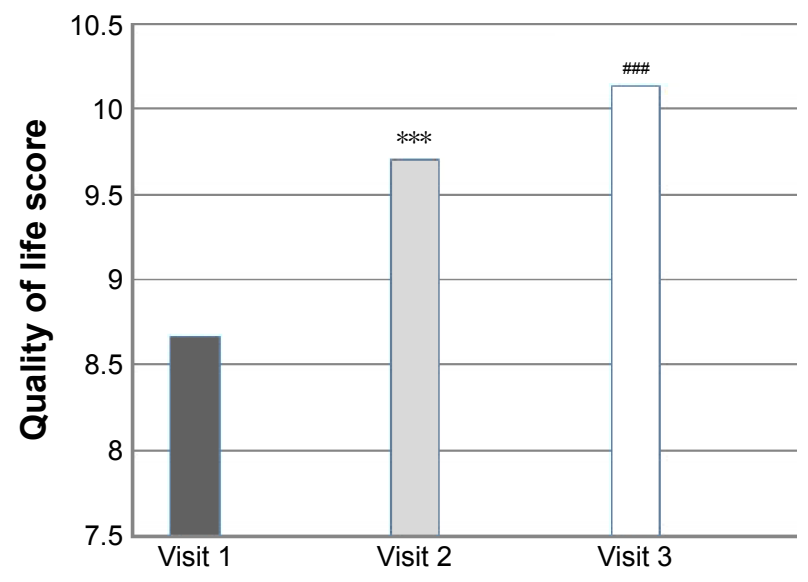

Figure 5 Comparison of quality of life score between visit I and visit 2, and visit I and visit 3.

Notes: ***VVisit I versus visit $2, P<0.00$ I, Student's $t$-test; $P<0.001$, Student's t-test. education on inhaler usage in real life. ${ }^{4}$ Patient education on good inhaler techniques ranges from "some education" $(67 \%-80 \%)$ to practical demonstration of usage (34\%-66\%) in different studies of this Italian group. ${ }^{4,9,10}$ In our study, the number of patients self-learning about device usage decreased by half from visit 1 to visit 3 .

There are many possible reasons why adherence to inhaled therapy is the main problem in treatment of asthma and COPD patients. ${ }^{11,12}$ Tarso et al associated incorrect inhaler usage with the presence of two or more comorbidities. ${ }^{13}$ The most important among them are presence of comorbidities, inhaler type, sociodemographic characteristics, and socioeconomic status. ${ }^{11,12}$ In the present study, male to female (M:F) ratio of patients with COPD and asthma was $1: 1.54$. There is no accurate local epidemiology data for 
the $\mathrm{M}: \mathrm{F}$ ratio of patients with $\mathrm{COPD} / \mathrm{asthma}$, since there is no national registry. However, based on worldwide data, the ratio 2:1 can be regarded as accurate for Europe, while the World Health Organization forsees the ratio in the near future to be $1: 1 .^{14,15}$ In our study, comorbidities were present in $42 \%$ of all patients, with hypertension $(20.2 \%)$ and allergic rhinitis $(5.1 \%)$ being the most prevalent. The most common risk factors for chronic respiratory disease were: smoking $(58 \%)$, positive family history of respiratory diseases (33\%), and exposure to fumes (12.5\%). Surprisingly, allergic rhinitis as a risk factor for development of respiratory diseases was less frequent in comparison to the literature data (5.1\%). ${ }^{16}$

The World Health Organization and the Global Alliance against Chronic Respiratory Diseases identified the most important risk factors for respiratory diseases as: tobacco smoke, indoor and outdoor air pollution, allergens, occupational agents, diet and nutrition, and pulmonary infections. ${ }^{16,17}$ Our patients were current or ex-smokers (58\%), had positive family history of asthma (33\%), and reported exposure to different fumes $(12.5 \%)$. We noticed that $70 \%$ of the risk factors in our study group were preventable. Such data should encourage school physicians, family care providers, professors, and also media to develop more aggressive prevention strategies regarding the above-mentioned detrimental risk factors, since their avoidance could preclude respiratory disease development.

Global Initiative for Chronic Obstructive Lung Disease and Global Initiative for Asthma reported 60\% uncontrolled COPD and asthma patients worldwide. ${ }^{1,3}$ Analyzing the level of disease control in our patient group, we found nearly 55\% of fully controlled disease status at the first visit. More importantly, the number of fully controlled patients constantly increased between visits 2 and 3 in comparison to visit 1 $(P<0.001)$. The fact that more than half of our patients still did not have comorbidities explains relatively high proportion of fully controlled disease at study entry. The former suggests that implementation of 3-month educational program gave important results. Melani concluded that education provided by pulmonologists has a key role in improving the inhaler technique and compliance. ${ }^{18}$ Results of evaluation of correctness of use of the inhaler during 3-month period showed changes in each of the seven steps during follow-up. At every visit, the investigator performed educational practical procedure, and consequently, significant improvement in correct use of drug device was found. It seems that the most difficult steps for a large number of patients (above 20\%) were those connected with grip twisting, breathing out, and after the drug inhalation - taking the device out from the mouth and breathing out (steps 3, 4, and 6, respectively). According to Fink and Rubin, up to $67 \%$ of health care professionals are unable to adequately describe or perform critical steps of inhaler use. ${ }^{8}$ This is an interesting point of view and suggests a need for registered professionals (trained in pharmaceutical companies, device manufacturers) to make harder efforts in education and training of health care professionals. However, an important result of this study was the significant improvement of about $20 \%$ in these three critical steps at visit 3 compared to visit 1 . Our results are comparable with those reported by Chang, who compared Turbuhaler and Swinghaler and found that the most critical steps were the same as we noticed. Jolly et al explained that increase of inhaler usage score is presumably dependent on practical educational training in every step. ${ }^{19,20}$ Their results showed significant increase in usage scores during three educational intervention sessions. Our experimental group also showed significant improvement in inhaling technique using Turbuhaler system between visits 1 and 3, as measured by inhaler usage score (5.94 and 6.82, respectively; $P<0.001)$. Calculation of the score enabled us to clearly point out progress in inhaler handling.

The data presented here allow us to make strategy aimed at improving all aspects of inhaler-related training and to identify the crucial problems in this process. Results of this study clearly speak in favor of pulmonologists, who are by far the most important educators for inhaler technique implementation. A randomized controlled trial that included practical education of the technique for a sample of more than 100 older patients with asthma showed that practical coaching, including verbal instruction and physical demonstration, was the most successful way for inhaler usage improvement, compared to passive education with written material. ${ }^{21}$ Melani et al stated that the busy clinical practice of recent times and frequent introduction of new devices launched as user friendly may cause reduced rates of inhaler usage education in practice. ${ }^{4}$

Takemura et al explained that giving repeated instructions for inhalation techniques contributes to adherence to the inhalation therapy, which is related to better "quality of life" score. ${ }^{22}$ Banfield and Murphy proposed establishing more effective patient-health care provider communication as the only way to identify nonadherence and for developing better adherence plan. ${ }^{23}$ Also, the issue of cost-effectiveness is more than important for patient satisfaction with the inhaler device as it not only positively correlates with lower treatment 
costs, but also with improved adherence and better quality of life that is reflected in the overall better health status of the patients..$^{24,25}$ On calculating the general "quality of life" score in our group of patients, we found stable augmentation in the quality of life of patients regarding absence of symptoms of chronic obstructive respiratory disease, therefore enabling them to do their everyday activities better. The most important finding of this study is that inhaler education and training program could positively influence the disease status, including causing an improvement in quality of life.

In conclusion, adherence to inhalation therapy is one of the key factors of successful respiratory disease treatment and we underline the need for broadening of correct inhaler usage-related educational programs performed by health care providers, especially pulmonologists, family physicians, and community public pharmacists. Improvement of patients' inhalation technique with different devices would result in better long-term disease control and improved quality of life.

\section{Acknowledgments}

This noninterventional study was sponsored by AstraZeneca, Representative Office Belgrade. Aleksandra Dudvarski Ilic, Branislava Milenkovic, Vujic Petrovic Tanja, Grujic Milan, Mitic Milikic Marija, Radovanovic Sanja, Zugic Vladimir, Krstic Svetlana, Percinkovski Malina, Radisavljevic Stasa, Stjepanovic Mihajlo, Danilovic Mirjana, Radulovic Vesna, Todorovic Vesna, Laban Zorica, Grubor Urosevic Mirjana, Todorovic Nada, Mikavica Ivana, Zorica Popovic, Uletilovic Tanja, Jauk Trojanovic Nada, Timotijevic Ljiljana, Branislava Djordjevic, Marinkovic Jasenka, Lekic Sladjana, Nikcevic Ljiljana, Zdravkovic Mihajlovic Aleksandra, Jovanovic Andjelka, Orlovic Smiljana, Vukadinovic Sofija, Dopudja Pantić Vesna, Petrovic Stanojevic Natasa, Culafic Milan, Djuric Vesna, Malicevic Hidajet, Stojanovic Ana, Stankovic Milanka, Klašnja Slobodan, Zvezdin Biljana, Sanja Hromis, Jelena Matic Jankov, Ilic Miroslav, Somborac Stevan, Balog Klajn Marta, Aranicki Nada, Kopitovic Ivan, Stanojev Dusica, Jovancevic Drvenica Mirjana, Maksimovic Olivera, Lazić Zorica, Djokić Zorica, Cekerevac Ivan, Videnovic Emilija, Vasic Dusica, Vrbic Biljana, Stankovic Ivana, Veljkovic Cvetkovic Vesna, Perhoc Nela, Zivkovic MIlivoje, Ciric Zorica, Dukic Jadranka, Vejnovic Milos, Seslija Siljanovic Gordana, Stankovic Dragan, Aleksandra Ponjevic Ogrizovic, and Jelacic Djordje were the study investigators.
Initial version of the manuscript was prepared by medical writer, Prof Jelena Kotur-Stevuljevic, and sponsored by AstraZeneca, Representative Office Belgrade.

\section{Disclosure}

The authors report no conflicts of interest in this work.

\section{References}

1. From the Global Strategy for the Diagnosis, Management and Prevention of $C O P D$, Global Initiative for Chronic Obstructive Lung Disease (GOLD); 2016. Available from: http://www.goldcopd.org/. Accessed April 21, 2016.

2. Institute of public health Serbia. Health and Statistical Report of the Republic of Serbia for 2014 year; 2014. Available from: http://www. batut.org.rs/download/publikacije/pub2014.pdf

3. From the Global Strategy for Asthma Management and Prevention, Global Initiative for Asthma (GINA); 2015. Available from: http:// www.ginasthma.org/

4. Melani AS, Bonavia M, Cilenti V, et al. Inhaler mishandling remains common in real life and is associated with reduced disease control. Respir Med. 2011;105(6):930-938.

5. Fink JB. Inhalers in asthma management: is demonstration the key to compliance? Resp Care. 2005;50(5):598-600.

6. Brzant L, Bang C, Chew C, Baik SH, Wiseman D. Adequacy of inhaler technique used by people with asthma or chronic obstructive pulmonary disease. J Prim Health Care. 2013;5(3):191-198.

7. Batherink J, Dahri K, Aulakh A, Rempel C. Evaluation of the use of inhaled medication by hospital in patients with chronic obstructive pulmonary disease. Can J Hosp Pharm. 2012;65(2):118-128.

8. Fink JB, Rubin BK. Problems with inhaler use: a call for improved clinician and patient education. Resp Care. 2005;50(10):1360-1374.

9. Rau JL. Practical problems with aerosol therapy in COPD. Respir Care. 2006;51(2):158-172.

10. Melani AS, Zanchetta D, Barbato N, et al; Associazione Italiana Pneumologi Ospedalieri Educational Group. Inhalation technique and variables associated with misuse of conventional metered-dose inhalers and newer dry powder inhalers in experienced adults. Ann Allergy Asthma Immunol. 2004;93(5):439-446.

11. Hughes CM. Medication non-adherence in the elderly: how big is the problem? Drugs Aging. 2004;21(12):793-811.

12. Di Matteo MR. Variations in patients' adherence to medical recommendations: a quantitative review of 50 years of research. Med Care. 2004;42(3):200-209.

13. Tarso P, Dalcin R, Grutcki DM, Lima PB, Menegotto SM, Pereira RP. Factors related to the incorrect use of inhalers by asthma patients. $J$ Bras Pneumol. 2014;40(1):13-20.

14. Adeloye D, Chua S, Lee C, et al; Global Health Epidemiology Reference Group (GHERG). Global and regional estimates of COPD prevalence: systematic review and meta-analysis. J Glob Health. 2015;5(2): 020415.

15. Chronic respiratory diseases: Burden of COPD. WHO; 2016. Available from: http://www.who.int/respiratory/copd/burden/en/. Accessed April 21, 2016.

16. World Health Organization. A world where all people breathe freely. In: Bousquet J, Khaltae N, editors. Global Surveillance, Prevention and Control of Chronic Respiratory Diseases: A Comprehensive Approach, 2007:30-34.

17. Melani AS, Paleari D. Maintaining control of chronic obstructive airway disease: adherence to inhaled therapy and risks and benefits of switching devices. COPD. 2016;13(2):241-250.

18. Melani AS. Inhalatory therapy training: a priority challenge for the physician. Acta Biomed. 2007;78(3):233-245. 
19. Chang YS, Park MJ, Bai C, et al. Comparative Study of Patients in Correct Usage of and Preference for the Swinghaler and Turbuhaler Multidose Inhaler. J of Asthma. 2012;49(7):750-756.

20. Jolly GP, Mohan A, Guleria R, Poulose R, George J. Evaluation of metered dose inhaler use and response to educational training. Indian $J$ Chest Dis Allied Sci. 2015;57(1):17-20.

21. Crane MA, Jenkins CR, Goeman DP, Douglass JA. Inhaler device technique can be improved in older adults through tailored education: findings from a randomised controlled trial. Prim Care Resp Med. 2014; 24:14034.

22. Takemura M, Mitsui K, Itotani R, et al. Relationships between repeated instruction on inhalation therapy, medication adherence, and health status in chronic obstructive pulmonary disease. Int J of COPD. 2011;6: 97-104.
23. Banfield J, Murphy KR. Adherence in asthma and COPD. Focus on asthma and COPD, Newsletter 11. Available from: http://advanceweb. com/web/AstraZeneca/focus_on_copd_issue11/focus_on_copd_issue11_ Adherence_in_asthma_and_copd.html. Accessed February 20, 2015.

24. Backer V, Hedegaard M, Larsson K. Adherence to inhaled therapies, health outcomes and costs in patients with asthma and COPD. Resp Med. 2013;107(10):1481-1490.

25. Leung JM, Bhutami M, Leigh R, Pelletier D, Good C, Sin DD. Empowering family physicians to impart proper inhaler technique to patients with chronic obstructive pulmonary disease and asthma. Can Resp J. 2015;22(5):266-270.

\section{Publish your work in this journal}

The International Journal of COPD is an international, peer-reviewed journal of therapeutics and pharmacology focusing on concise rapid reporting of clinical studies and reviews in COPD. Special focus is given to the pathophysiological processes underlying the disease, intervention programs, patient focused education, and self management protocols.

\section{Dovepress}

This journal is indexed on PubMed Central, MedLine and CAS. The manuscript management system is completely online and includes a very quick and fair peer-review system, which is all easy to use. Visit http://www.dovepress.com/testimonials.php to read real quotes from published authors.

Submit your manuscript here: http://www.dovepress.com/international-journal-of-chronic-obstructive-pulmonary-disease-journal 